\title{
Biodiesel from Sesame Oil: Base Catalyzed Transesterification
}

\author{
Kaniz Ferdous $^{1 *}$, M. Rakib Uddin ${ }^{1}$, Maksudur R. Khan ${ }^{1,2}$, and M. A. \\ Islam $^{1}$ \\ ${ }^{1}$ Department of Chemical Engineering and Polymer Science, ShahJalal \\ University of Science and Technology, Sylhet-3114, Bangladesh. \\ ${ }^{2}$ Faculty of Chemical and Natural Resources Engineering, University Malaysia \\ Pahang, 26300 Gambang, Kuantan, Pahang, Malaysia. \\ *Corresponding Author e-mail: engr_kaniz@yahoo.com
}

\begin{abstract}
A process for the production of methyl ester from Sesame oil containing $6.1 \%$ free fatty acid (FFA) for the use as a biodiesel was studied. These studies were carried out on transesterification reaction of Sesame oil with methanol to produce biodiesel. The reaction parameters such as Methanol/Oil molar ratio, catalyst concentration and reaction time were optimized for the production of sesame oil methyl ester (SOME). Conversion of triglyceride has been monitored from viscosity measurement and also by measuring produced glycerin concentration. Pseudo first order kinetic model has been proposed for the transesterification of Sesame oil to biodiesel and the data are fitted with the model to evaluate the kinetic parameters. Biodiesel properties such as cetane number, kinematic viscosity, flash point, pour point, cloud point are measured and compared with biodiesel and petrodiesel standard.
\end{abstract}

Keywords: Biodiesel, Catalyst, Glycerin, Sesame oil, Transesterification.

\section{Introduction}

As the global debate over reducing the dependence on fossil fuel heats up, discussion of alternative fuels is more and more prevalent. One of the most commonly mentioned is biodiesel; a 100\% agriculturally derived liquid fuel, often called B100. Most often used as fuel in diesel vehicle engines, biodiesel can also 
be used as heating oil. Biodiesel is made from virgin vegetable oils, from waste frying oils or from waste animal fats and oils. It can be used alone or blended with petroleum diesel in any percentage without major modifications to the engine ${ }^{[1-2]}$.

The feedstock for biodiesel production can vary from country to country depending on the availability of certain types of vegetable oil. For example the vegetable oils such as soybean oil in USA, rapeseed oil in Europe, palm oil in Malaysia and Jatropha in India are being used for the production of biodiesel to fuel their compression ignition engines ${ }^{[3]}$.

Transport sector of Bangladesh mainly use petrol, diesel and compressed natural gas (CNG). There are estimates that the resources for Natural Gas are being depleted and in fact, could hit rock bottom by the year $2020^{[4]}$. Presently Bangladesh imports 2.4 million metric ton diesel fuel each year.

The entire amount is imported from Kuwait, Saudi Arabia, the United Arab Emirates and India costing over $\$ 2$ billion ${ }^{[5]}$. Demand for diesel surged by around 15 per cent in recent months due to its increased use in captive generators in industries, commercial establishments and apartments as the country has been hit by power shortfall. Higher consumption of diesel, which accounts for approximately 60 percent of total import of petroleum products, will create a fresh pressure on the country's fuel import bill this fiscal ${ }^{[6]}$. Diesel is also used in the irrigation pumps and in the transportation sector. To meet the increasing demand of diesel, biodiesel may be an alternative source. The production of the oil seeds such as mustard, groundnut, linseed, castor, coconut and sesame is $~ 384115$ MTons/year, in which sesame seeds are produced around 11000 MTons/year ${ }^{[7]}$. The present number is not satisfactory for the production of biodiesel from sesame oil in Bangladesh. Additional sesame can be grown on a massive scale in the unused lands, which accounts around 0.32 million hectare ${ }^{[5]}$ and in that case sesame oil can be considered as an alternative source for biodiesel production. Sesame oil is mainly composed of triglycerides of the singly saturated oleic acid $(43 \%)$, doubly saturated linoleic acid (35\%), palmitic acid (11\%) and stearic acid $(7 \%)^{[8]}$. Because of its excellent antioxidant property, sesame oil has an excellent self life. Moreover, it is a non drying oil and highly stable rarely turning rancid in hot climates.

In the present paper biodiesel has been prepared from sesame oil by base catalyzed transesterification reaction with methanol. Effect of different reaction parameters such as Methanol/Oil molar ratio and catalyst concentration has been studied and optimum parameters have been found. Kinetics of the tranesterification reaction has been studied and pseudo first order kinetic equation was proposed. The experimental data was fitted to this model. 


\section{Materials and Methods}

\subsection{Chemicals}

Methanol (99-100\%), ethanol (99-100\%), sodium hydroxide pellets (96\%), potassium hydroxide pellets (>84\%), phenolphthalein ( $\mathrm{pH} 8.2$ - 9.8), starch, acetone (99\%), benzene, sodiumthiosulfate (99.0\%), n-Hexane (96\%), hydrochloric acid (37\%), sulfuric acid (98\%), isopropanol, iodine, sodium iodide, glacial acetic acid, bromine, carbon tetrachloride, phosphoric acid (85\%), sDiphenylcarbazide, Potassium Dichromate etc. were purchased from Merck, Germany. All the chemicals used were analytical reagent grade.

\subsection{Extraction of oil}

Sesame seeds were collected from local market. Oil from the seed was extracted by mechanical press. A vertical, manual operated, cylindrical $(4.3 \mathrm{~cm} \mathrm{ID})$ mechanical press was constructed which have a spiral screw that conveys the mass from the hoper to pressure raising area. Slow and continuous rotation of the press allows raising sufficient pressure for the extraction of oil. The spiral screw is used for random mixing and size distribution. Oil drainage nozzles are located in the face of the expeller. At first the sesame seed were smashed and then oil was extracted from the smashed mass. In that process, $20 \mathrm{~mL}$ solvents (n-hexane) was mixed with $50 \mathrm{gm}$ of smashed sesame seed; then oil extracted from the seed. After oil extraction it was filtered and solvent was evaporated in rotary evaporator under vacuum at $60{ }^{\circ} \mathrm{C}$. The oil content of sesame seed was found $35 \%(\mathrm{v} / \mathrm{w})$.

\subsection{Synthesis of biodiesel by transesterification}

Biodiesel from sesame oil was synthesized by base catalyzed transesterification reaction ${ }^{[9]}$. The reaction was carried out at $60{ }^{\circ} \mathrm{C}$ and atmospheric pressure under reflux for 90 minutes with vigorous stirring. Typically $50 \mathrm{gm}$ of oil sample were placed in a two-necked $250 \mathrm{~mL}$ round bottom flask equipped with a reflux condenser. The flask was immersed in an oil bath with a temperature controller and magnetic stirrer. Sodium hydroxide pellets ( $1 \mathrm{wt} \%$ of oil) was dissolved in required amount of methanol. Methanol was used 6:1 molar ratio to oil. The sodium-methoxide solution was transferred into the reaction flask. After 90 minutes the reaction was stopped by adding required stoichiometric amount of concentrated hydrochloric acid and then the contents were cooled to room temperature. After the reaction period, the reaction product was allowed to stand 12-14 hour in a separatory funnel. Three separate layers were observed. Upper layer was excess methanol, middle layer was methyl ester (Biodiesel) and lower layer were a mixture of soap, crude glycerin and lye catalyst. The Biodiesel layer was separated and this layer was opaque as it contained some catalyst, methanol, triglyceride and soap. 
For purification of the biodiesel a bubble washing technique was employed. For this purpose hot water was placed in a funnel while air was pumped from the bottom of the porous support to produced small air bubbles. Biodiesel was poured on the water layer. As the bubbles raised biodiesel were coated with water, picked up impurities as it traveled up and then back down to the water through the biodiesel. Finally when a transparent layer of biodiesel was observed then disconnected from the flask. The washed biodiesel was then dried at $80-100{ }^{0} \mathrm{C}$ under vacuum in rotary evaporator.

Glycerin, catalyst and soap were remained in the bottom layer. Glycerin was separated by adding required stoichiometric amount of $85 \%$ concentrated phosphoric acid to the bottom layer. The required amount was $0.4 \mathrm{~mL} \mathrm{H}_{3} \mathrm{PO}_{4}$ per $5 \mathrm{~mL}$ of precipitate. As a result the catalyst was precipitated out and the soap was converted to FFA, which floated on the top. Weight of the produced glycerin was measured. The effect of different oil to methanol molar ratio and catalyst concentration was observed.

\subsection{Calibration curve for determining conversion of biodiesel by viscosity method}

Viscosity of raw sesame oil was $52.5 \mathrm{~mm}^{2} / \mathrm{s}$. At first certain amount of sesame oil undergoes base catalyzed transesterification reaction, mention above and biodiesel was produced. This produced biodiesel were separates and again undergoes base catalyzed transesterification and the produced biodiesel was assumed 100\% biodiesel and viscosity was measured. Then different proportion of raw sesame oil was blended with produced biodiesel and the viscosity of each blend was measured. And the percentage conversion was calculated from the viscosity change. Viscosity vs percentage conversion plot was presented in Fig. 1 which used for the determination of conversion giving transesterification reaction.

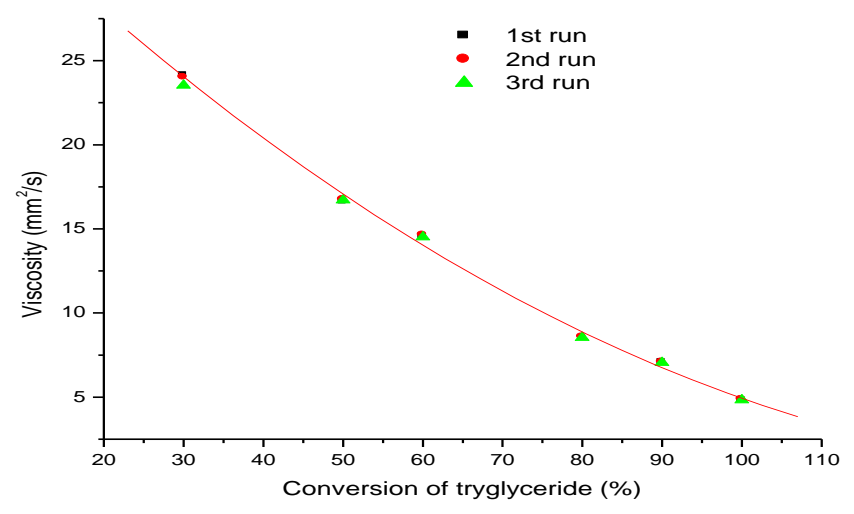

Fig. 1: Viscosity Vs Conversion of Biodiesel [Viscosity measured at $40{ }^{\circ} \mathrm{C}$, Reaction temp. $60{ }^{\circ} \mathrm{C}$, Oil / methanol molar ratio 1:6, Catalyst concentration $1 \mathrm{wt} \%$ of oil and Reaction time 90 min under reflux with vigorous stirring]. 


\subsection{Analytical Methods for Oil and Biodiesel}

FFA in the oil and biodiesel samples was analyzed by the method described in AOCS Aa 6-38 $8^{[10]}$. To determine FFA of sample, 4-5 gm of samples were dispersed in isopropanol $(75 \mathrm{~mL})$ and hexane $(15 \mathrm{~mL})$ followed by titration against $0.25 \mathrm{~N} \mathrm{NaOH}$. Saponification value (SV) was determined by the method described by Jeffery et al ${ }^{[11]}$. To determine SV of Sample, 1gm of sample was taken with $25 \mathrm{~mL}$ alcoholic $\mathrm{KOH}$ in a round bottom flask, heated for one hour in a steam bath with occasional shaking and titrated the excess $\mathrm{KOH}$ with the $0.5 \mathrm{M}$ hydrochloric acid. The concentration of produced glycerin in the reaction was measured by standard colorimetric method ${ }^{[12]}$. The iodine value (IV) were determined by titrating $0.01 \mathrm{~N}$ sodium thiosulfate to the mixture of tested fuel and chemical reagents until the disappearance of the blue color based on the analysis methods of American Oil Chemist's Society ${ }^{[10]}$. IV was calculated by the following equation (1).

$\mathrm{IV}=(B-S) \times N \times 0.001269 / \mathrm{W}$

where, $S$ and $B$ are the amounts (in unit of $\mathrm{mL}$ ) of sodium thiosulfate titrated for the tested sample and blank sample respectively; $N$ is the molar concentration (in unit of mol/L) of sodium thiosulfate and $W$ is the weight (in unit of gm) of the tested sample.

Physical properties such as moisture content and specific gravity of the oil were determined by following ASTM D 1744 (Karl fisher method) and ASTM D 1480/81 respectively. Viscosity, calorific value, flash point, pour point and cloud point were determined by standards ASTM D445, ASTM D 240, ASTM D 93 (Pensky- Martens Flashpoint Apparatus, Lazer Scientific Inc, Germany), ASTM D 2500 and ASTM D 97 respectively.

\section{Results and Discussion}

\subsection{Characterization of sesame oil}

The properties of raw oil, such as the specific gravity, kinematic viscosity, FFA content, moisture content, saponification value, iodine value was measured by the methods was mentioned above and presented in Table 1 . 
Table 1: Properties of raw sesame oil

\begin{tabular}{cc}
\hline Properties & Value \\
\hline Specific gravity at $25^{\circ} \mathrm{C}$ & 0.88 \\
Kinematic viscosity $\left(\mathrm{mm}^{2} / \mathrm{s}\right)$ at $40{ }^{\circ} \mathrm{C}$ & 52.5 \\
FFA $(\mathrm{wt} \%)$ & 6.1 \\
Moisture content $(\mathrm{ppm}$ by wt.) & $0.08 \%$ \\
Iodine value $\left(\mathrm{gm} \mathrm{I}_{2} / 100\right.$ gm oil) & 75.3 \\
$\mathrm{pH}$ & 7.2 \\
Saponification value $(\mathrm{mg} \mathrm{KOH} / \mathrm{gm}$ oil $)$ & 213 \\
\hline
\end{tabular}

\subsection{Transesterification of sesame oil}

\subsubsection{Effect of oil/ methanol molar ratio}

The oil to alcohol molar ratio is one of the important factors affecting the conversion of transesterification reaction of sesame oil to biodiesel. Methanolysis of sesame oil was carried out with catalyst concentration $1.0 \mathrm{wt} \%$ of oil at $60{ }^{\circ} \mathrm{C}$ and vigorous stirring with different oil/ methanol molar ratio e.g. 1:4.5, 1:6, 1:9 and 1:12 and the results are given in Fig. 2.

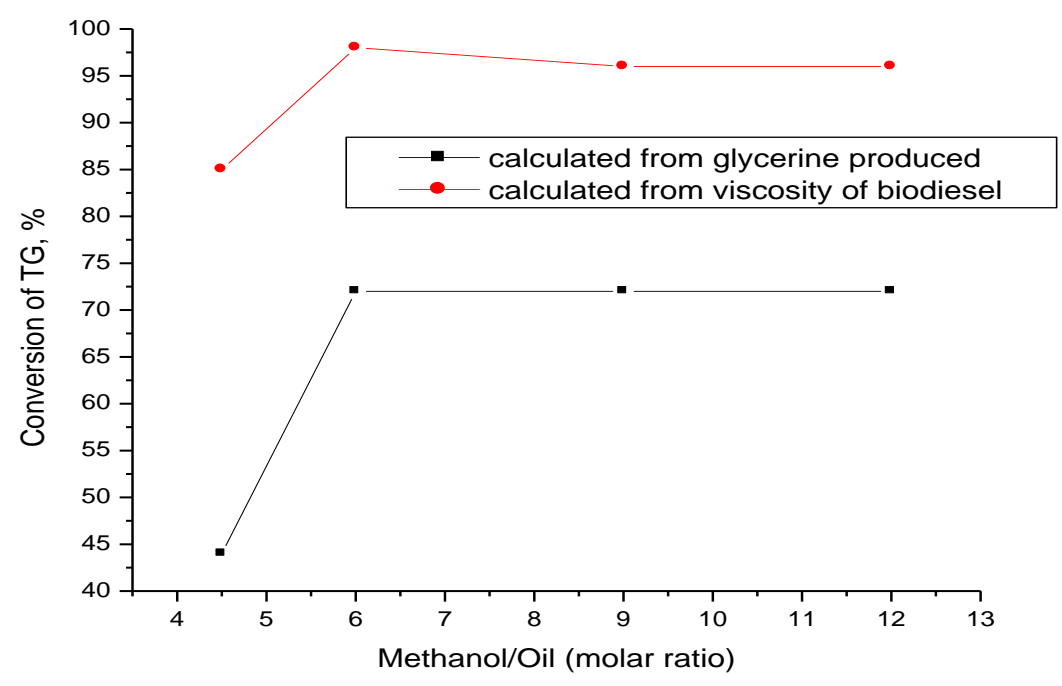

Fig. 2: conversion of sesame oil to biodiesel at different oil/ methanol molar ratio [Reaction temp. $60{ }^{\circ} \mathrm{C}$, Catalyst concentration $1 \mathrm{wt} \%$ of oil and Reaction time 90 min under reflux with vigorous stirring].

From Fig.2, it shows that the maximum conversion of sesame oil to biodiesel was found for oil /methanol molar ratio of 1:6 after 90 minutes and the conversion was $98.0 \%$ in terms of kinematic viscosity and $72 \%$ in terms of glycerin concentration. For both measurement methods, the conversion trends are same for same oil/ 
methanol molar ratio. In case of molar ratio 1: 4.5 the reaction time was not sufficient to accomplish the desired conversion. However, the high molar ratio of alcohol to sesame oil interferes with the separation of glycerin because there is an increase in solubility. When glycerin remains in solution, it helps drive the equilibrium to back to the left lowering the yield of biodiesel.

\subsubsection{Effect of catalyst concentration on transesterification}

The conversion of sesame oil to biodiesel is greatly affected by catalyst concentration. Biodiesel conversion was measured by both measuring the concentration of glycerin produced in reaction and the kinematic viscosity of the produced biodiesel. Methanolysis of sesame oil was carried out with $\mathrm{NaOH}$ as a catalyst at concentration range from $0.25-1.5 \mathrm{wt} \%$ of oil at $60{ }^{\circ} \mathrm{C}$ with oil/methanol molar ratio of 1: 6 . The results are given in Fig. 3.

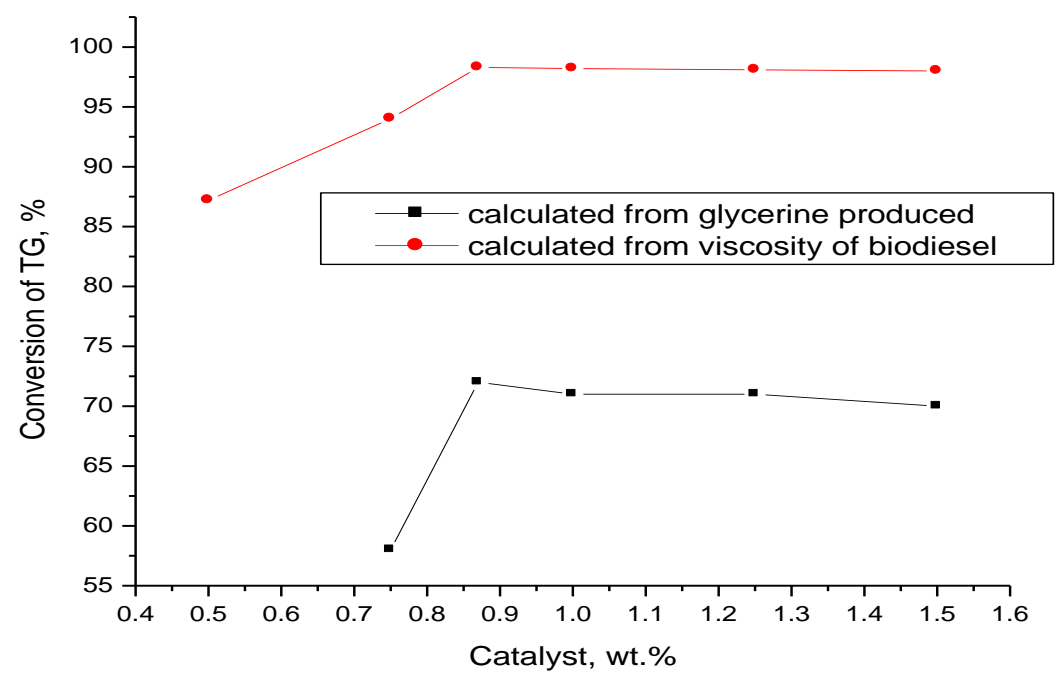

Fig. 3: conversion of sesame oil to biodiesel at different catalyst concentration [Reaction temp. $60^{\circ} \mathrm{C}$, oil / methanol molar ratio 1:6 and Reaction time $90 \mathrm{~min}$ under reflux with vigorous stirring].

From the Fig. 3, it shows that the lower catalyst concentration i.e. $0.25 \mathrm{wt} \%$ $\mathrm{NaOH}$ of oil was insignificant to catalyze when the conversion of sesame oil to biodiesel was measured in terms of glycerin concentration and conversion was $87.2 \%$ from oil to biodiesel when measured in terms of kinematic viscosity. However $0.87 \mathrm{wt} \% \mathrm{NaOH}$ of oil was optimal in the reaction both measurement with a conversion of $72 \%$ in terms of produced glycerin concentration and with a conversion of $98.3 \%$ in terms of kinematic viscosity in just 90 minutes. With the increase in concentration of catalyst, there was decrease in the yield of methyl ester. This was in accordance with the result obtained by Dorado et al. (2004) ${ }^{[13]}$ 
and was due to the formation of soap in presence of high amount of catalysts, which increased the viscosity of the reactants and lowered the conversion. Conversion of triglyceride found by glycerin determination method was lower than that of determined by viscosity method. The lower conversion from the result was expected as considerable amount of glycerin was lost during the separation of glycerin layer and some of the glycerin remained in the biodiesel layer.

\subsection{Kinetic study of transesterification}

The overall transesterification reaction can be written in following form:

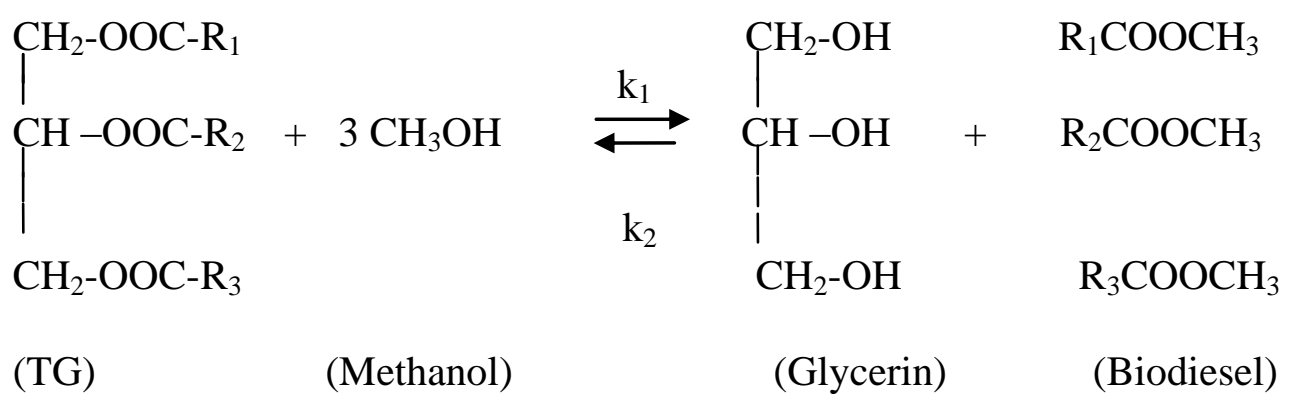

where, $R_{1}, R_{2}$ and $R_{3}$ denotes any alkyl hydrocarbon chain.

According to stoichiometry of the reaction above, the overall reaction rate can be written as,

$$
\begin{aligned}
& \text { Rate }=-\frac{d[T G]}{d t}=\frac{d[G]}{d t} \\
& =k_{1}[T G][\mathrm{MeOH}]^{3}-k_{2}[\mathrm{ME}]^{3}[G]
\end{aligned}
$$

Equilibrium constant,

$$
K=\frac{[M E]^{3}[G]}{[T G][\mathrm{MeOH}]^{3}}=\frac{k_{1}}{k_{2}}
$$

where, $[\mathrm{ME}],[\mathrm{G}],[\mathrm{TG}]$ and $[\mathrm{MeOH}]$ are the concentration of biodiesel, glycerin, triglyceride and methanol respectively. $\mathrm{k}_{1}$ and $\mathrm{k}_{2}$ are forward and backward reaction rate constant. Since, methanol used as excess reactant with respect to TG; we considered the overall transesterification as pseudo first order reaction. Then equation (2) and (3) reduced to

$$
\text { Rate }=\frac{d[T G]}{d t}=\frac{d[G]}{d t}=k_{1}[T G]-k_{2}[G]
$$


Equilibrium constant,

$K=\frac{k_{1}}{k_{2}}=\frac{[G]_{e}}{[T G]_{e}}$

where $[\mathrm{G}]_{\mathrm{e}}$ and $[\mathrm{TG}]_{\mathrm{e}}$ are the equilibrium concentration of glycerin and triglyceride respectively. Equilibrium constant, $\mathrm{K}$ can be determined experimentally. All the values of the equation were expressed in terms of glycerin concentration and the value of equilibrium constant was, $\mathrm{K}=2.6$.

Equation (4) can be rewritten as

$\frac{1}{b} \ln \frac{a}{a-b[G]}=k_{1} t$

and

$[G]=\frac{a}{b}\left\{1-\exp \left(-b k_{1} t\right)\right\}$

at $\mathrm{t} \rightarrow \infty$, equation $(7)$ reduces to $[\mathrm{G}]_{\infty}=\frac{\mathrm{a}}{\mathrm{b}}$

where, $\mathrm{a}=[\mathrm{TG}]_{0}$ and $\mathrm{b}=1+1 / \mathrm{K}$.

Experimental data is fitted in equation (6) and the forward reaction rate constant is evaluated and the value is $0.068 \mathrm{~min}^{-1}$. By using the value of $\mathrm{k}_{1}$ in equation (7) we can find the theoretical concentration of glycerin with respect to time. Plot glycerin concentration (theoretical and experimental) vs time shown in Fig. 4. From the concentration of glycerin we can find the conversion of sesame oil to biodiesel.

\subsection{Properties of produced biodiesel}

Properties of the produced biodiesel and comparison with biodiesel and petrodieselstandard are given in Table 2.

The quality of biodiesel was determined by measuring some property such as cetane number which indicates ignition characteristic. Cetane number of biodiesel was slightly lower than standard value of biodiesel. But the cetane number of the blend of sesame oil with petro diesel was higher than standard value of biodiesel. Flash point of the produced biodiesel was higher than petro-diesel which is safe for transport purpose ${ }^{[1]}$. Other properties such as kinematic viscosity, cloud point, pour point, density, $\mathrm{pH}$, saponification value etc. were measured. 


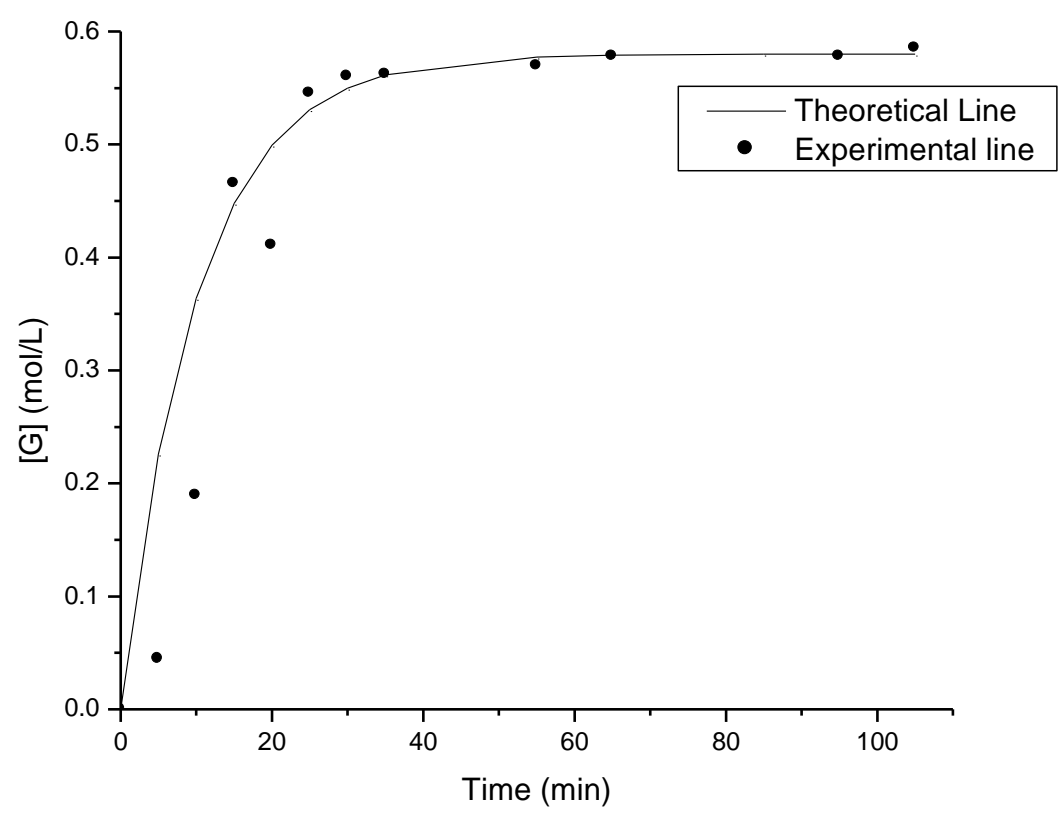

Fig. 4: Concentration of produced glycerin-Time curve for transesterification reaction.(Dense line-theoretical, Points-experimental) [Reaction temp. $60{ }^{\circ} \mathrm{C}$, oil/methanol molar ratio 1:6 and Catalyst concentration $0.87 \mathrm{wt} \%$ of oil under reflux with vigorous stirring].

\section{Conclusion}

Biodiesel has been synthesized from sesame oil by base catalyzed transesterification reaction. Raw sesame oil has $6.1 \%$ FFA content. The properties of the raw oil were investigated, kinematic viscosity of raw oil were $52.5 \mathrm{~mm}^{2} / \mathrm{s}$, saponification value and density were $213 \mathrm{mg}$ of $\mathrm{KOH} / \mathrm{gm}$ of oil and $0.88 \mathrm{gm} / \mathrm{cm}^{3}$ respectively. The optimum condition for the base catalyst transesterification reaction was determined. The optimum condition for the base catalyst transesterification reaction was $0.87 \mathrm{wt} \% \mathrm{NaOH}$ to oil as catalyst, methanol/oil molar ratio of $6: 1$ and the maximum conversion was $98.3 \%$ from oil to biodiesel at 90 minutes.A significant reduction of viscosity and acid value was found. The properties, such as specific gravity, viscosity, flash point, cloud point, pour point and calorific value are comparable with the standard value of biodiesel and petrodiesel. The present experimental results support that biodiesel from sesame seed oil can be successfully used as diesel. 
Table 2: Properties of biodiesel produced from sesame oil and comparison with standard value

\begin{tabular}{|c|c|c|c|}
\hline Properties & $\begin{array}{c}\text { Produced } \\
\text { Biodiesel Value }\end{array}$ & $\begin{array}{c}\text { Biodiesel } \\
\text { Standard }{ }^{[14-15]}\end{array}$ & $\underset{[15]}{\text { Diesel Standard }}$ \\
\hline Specific gravity at $25{ }^{\circ} \mathrm{C}$ & 0.85 & $0.88\left(\right.$ at $\left.15.5^{0} \mathrm{C}\right)$ & 0.85 (at $15.5^{0} \mathrm{C}$ ) \\
\hline $\begin{array}{c}\text { Kinematic viscosity }\left(\mathrm{mm}^{2} / \mathrm{s}\right) \text { at } \\
40{ }^{\circ} \mathrm{C}\end{array}$ & 5.47 & $1.9-6.0$ & $1.3-4.1$ \\
\hline Calorific value $(\mathrm{MJ} / \mathrm{kg})$ & 34.6 & - & 42 \\
\hline FFA $(w t \%)$ & 0.4 & Trace & - \\
\hline Cetane no & 40 & $44-49$ & - \\
\hline Cetane number of * $\mathrm{B} 20$ & 51.2 & - & - \\
\hline Cetane number of ${ }^{*} \mathrm{~B} 50$ & 46.4 & - & - \\
\hline Flash point $\left({ }^{\circ} \mathrm{C}\right)$ & 185 & 100 to 170 & 60 to 80 \\
\hline Cloud point $\left({ }^{\circ} \mathrm{C}\right)$ & -5 & -3 to 12 & -15 to 5 \\
\hline Pour point $\left({ }^{\circ} \mathrm{C}\right)$ & -8 & -15 to 10 & -35 to -15 \\
\hline Moisture content (ppm by wt.) & $0.15 \%$ & $0.05 \%$ & 161 \\
\hline $\begin{array}{l}\text { Iodine value ( } \mathrm{gm} \mathrm{I}_{2} / 100 \mathrm{gm} \\
\text { oil) }\end{array}$ & 61.2 & - & - \\
\hline $\mathrm{pH}$ & 7.5 & $6.5-7.5$ & - \\
\hline Free glycerol, wt $\%$ & Nil & $0.02 \max$ & - \\
\hline Total glycerol, wt $\%$ & Nil & $0.24 \max$ & - \\
\hline $\begin{array}{l}\text { Saponification value (mg } \\
\mathrm{KOH} / \mathrm{gm} \text { oil) }\end{array}$ & 206 & - & - \\
\hline
\end{tabular}

\section{References}

[1] F. Ma., M.A. Hanna, Biodiesel production: a review, Bioresource Technology 70(1) (1999) 1-15.

[2] L.C. Meher, S.D. Vidya, S.N. Nnik, Technical aspects of biodiesel production by transesterification - a review, Renewable and sustainable Energy Review 10 (2006) 248-268.

[3] G. Knothe, Synthesis and characterization of long chain 1,2dioxo compounds, Chemistry and Physics of Lipids 115 (2002) 85-91.

[4] http://www.bangladesh2020.wordpress.com/biofuel-the-fuel-of-the future.html. Revised May 2008. Accessed January 01, 2010.

[5] M. N. Nabi, S.M. N. Hoque, M. S. Akter, Karanja (PongamiaPinnata) biodiesel production in Bangladesh, characterization of karanja biodiesel and its effect on diesel emissions, Fuel Processing Technology 90(9) (2009) 1080-1086. 
[6] http://www.thefinancialexpress-bd.com/2009/07/11/72670.html.(BPC to the Financial Express). Revised July 2009. Accessed July 26, 2019.

[7] Statistical Pocket Book, Bangladesh, 2005.

[8] M. Elluch, S. Besbes, O. Roiseux, C. Blecker, H. Attia, Quality Characteristic of Sesame Seed and by-products, Food Chemistry 103 (2007) 641-650.

[9] A. Saydut, M.Z. Duz, C. Kaya, A.B. Kafadar, C. Hamamci, Transesterified sesame (Sesamumindicum L.) seed oil as a biodiesel fuel, Bioresource Technology 99 (2008) 6656-6660.

[10] Official Methods and Recommended Practices of the American Oil Chemists Society, 5th edition, AOCS Press, Champaign, 1998, pp. 6-38.

[11] G.H. Jeffery, J. Bassett, J. Mendham, R. C. Denney, Vogel's Textbook of Quantitative Chemical Analysis, 5th edition, Longman Scientific and Technical, UK, 1991, pp. 308-309.

[12] V.H. Reese, Max B. Williams, Colorimetric Determination of Giycerol, Analytical chemistry 26(3) (1954) 568-570.

[13] M.P. Dorado, E. Ballesteros, M. Mittelbach, F.J. Lopez, Optimization of alkali-catalyzed transesterification of brassica carinata oil for biodiesel production, Energy and fuels, 18 (2004) 77-83.

[14] D.Y.C. Leung, Xuan Wu, M.K.H. Leung, A review on biodiesel production using catalyzed transesterification, Applied Energy 87 (2010) 1083-1095.

[15] R.M. Joshi, M.J. Pegg, Flow properties of biodiesel fuel blends at low temperatures, Fuel 86 (2007) 143-151. 